Reprinted from The American Journal of Physiology

Vol. 88, No. 1, February, 1929

\title{
THE RESPONSE OF ISOLATED SEGMENTS OF INTESTINE AND UTERUS TO ADRENALIN AT DIFFERENT pH LEVELS OF THE BATH
}

\author{
G. R. SUCKOW AND G. E. BURGET \\ From the Department of Physiology, University of Oregon
}

Received for publication October 16, 1928

It has been shown that the response of the vascular system of the pithed cat to adrenalin varies with the $\mathrm{pH}$ of the blood (Burget and Visscher, 1927). This difference in response of the vascular system to adrenalin when the $\mathrm{pH}$ of the blood is altered is due to a change in irritability at the site of action of the drug (Burget and Crisler, 1927). These findings apply to the vasoconstrictor mechanism only. The present work was undertaken to determine whether or not the inhibitory innervation to the intestine undergoes similar changes in irritability when the $\mathrm{pH}$ of the bath is altered. Many investigators have studied the differences in activity of intestine and uterine segments upon varying the hydrogen ion concentration of the bath in which they were suspended (Evans and Underhill, 1923; Acton and Chopra, 1925; Thienes, 1926) but no attempt has been made to determine the influence of the hydrogen ion concentration of the bath upon the irritability of the inhibitory mechanism of the intestine. Adrenalin was used because it lent itself well for this purpose.

Thirty-five young adult female rabbits were used in this series. The animals were killed at approximately one-thirty o'clock in the afternoon of the day of the experiment by being struck upon the occiput. It was noticed that in every case the animal's stomach was distended with food when the evisceration was made. The diet of the animals consisted of barley and carrots. This diet factor was especially watched for the effect it might have upon the activity of the tissue. Approximately five minutes after the death of the animal the following different methods were used in preparing the tissues: $a$, the tissues to be used were washed carefully inside and outside with 0.9 per cent saline solution and then mounted immediately in the contraction vessel; $b$, mounted immediately without washing; $c$, washed as above, placed for two hours in the refrigerator in a closed vessel at about $10^{\circ} \mathrm{C}$. and then mounted; $d$, immediately put in the refrigerator, left there for two hours at $10^{\circ} \mathrm{C}$. in a closed vessel, and then mounted without any preliminary washing, and $e$, the unwashed tissues, having been kept for two hours in the refrigerator at $10^{\circ} \mathrm{C}$., were washed 
with 0.9 per cent saline and then mounted. These preliminary segregations were made in an attempt to explain a "drug action fading phenomenon" to be discussed later in this paper. Tissues over two hours old in most cases proved unsatisfactory for the purposes of this experiment.

Segments of proximal duodenum, proximal jejunum, lower ileum, scybalar colon, and uterus were employed. Gut segments $2 \mathrm{~cm}$. long, and cornate segments of uterus $2 \mathrm{~cm}$. long, were used. Since only one horn of the uterus could be used at a time in each experiment, the other horn was left intact and freely suspended in the bath.

The bath consisted of Locke's mammalian solution, kept at $37.0^{\circ} \mathrm{C}$., with a variation of $1.0^{\circ} \mathrm{C}$. either way which occurred not faster than $1.0^{\circ} \mathrm{C}$. per half-hour. Air was bubbled through from an immersed glass tube of $3 \mathrm{~mm}$. internal diameter at a constant rate of approximately 300 bubbles per minute. The volume of the tissue bath was $250 \mathrm{cc}$. In order to keep the temperature constant, this bath was surrounded by another bath of 1000 cc. volume, the latter bath being heated by a carefully regulated micro-burner.

Estimations of $\mathrm{pH}$ on the bath were made by withdrawing $5.0 \mathrm{cc}$. with a calibrated pipette, adding $0.25 \mathrm{cc}$. phenol red solution in alcohol, and comparing colorimetrically to a phenol red set of standards (McCrudden, 1922; Dale and Evans, 1920). This method was found to be accurate enough for the purpose of these experiments. Changes in the $\mathrm{pH}$ could be made at will by the addition of $\mathrm{N} / 10 \mathrm{NaOH}$ and $\mathrm{N} / 10 \mathrm{HCl}$ in drop fractions. To allow for a more thorough mixture in the solvent of the acid or alkali, the drug was added about two minutes after the addition of the acid or alkali. $\mathrm{pH}$ estimations were made immediately after adding the drug.

Bath $\mathrm{pH}$ variations were also effected and studied by exchanging an acid bath for a basic bath, and vice versa, instead of altering the $\mathrm{pH}$ of a single bath.

Adrenalin chloride (Parke, Davis \& Co.) in $1 / 1000$ solution was used. Fresh dilutions of $1 / 10,000$ were made before each experiment. It was assumed that the chloretone content would be negligible, since this as a factor has been shown by previous investigators to play a small rôle in the action of the drug on the tissues employed. The drug was added to the bath by a drop method from a standard pipette kept for this purpose only. The concentrations of the drug in the bath ranged from $1 / 8,000,000$ to $1 / 25,000,000$ (however, a constant concentration was used through each experiment). The minimal amount that would cause a depression that could be compared quantitatively to a depression caused by a similar dose at a different $\mathrm{pH}$, was employed. Experiments. were also done using adrenalin hydrochloride tablets, which were dissolved in 0.9 per cent saline to make a $1 / 10,000$ solution.
The $\mathrm{pH}$ of the bath was varied within the limits 6.5 and 8.3 , but most of the observations were made within the limits 7.3 to 8.3 . It was deemed necessary to vary this much past the physiological limits of blood in order to try the wider $\mathrm{pH}$ range which might exist in the living tissues as well as to amplify the gradations in response which might be produced, without any great change in muscle tone.

REsults. The results of Evans and Underhill (1923) and Sollmann, von Oettingen and Ishikawa (1928) on the activity of segments of small intestine and uterus when the $\mathrm{pH}$ of the bath is altered were confirmed. With segments of small intestine, sudden drops of $\mathrm{pH}$ down to 6.5 or even to 6.8 stopped the contractions and produced relaxation, with a permanent loss of tonus, unless the media $\mathrm{pH}$ was again raised. A change to the acid side of neutrality caused a decrease in the amplitude of the rhythmical contractions. A sudden change in the opposite direction, e.g., to a $\mathrm{pH}$ 8.0 produced an increase of tonus, usually with an increase of amplitude. Sometimes with a high $\mathrm{pH}$ value the amplitude of the rhythmical contractions was reduced. Sudden increases of $\mathrm{pH}$ caused sudden increases of tonus. Gradual increases of $\mathrm{pH}$ caused less alteration in tone but more marked changes in the rhythmical contractions (causing them to increase in rate and amplitude). The rhythmical contractions appeared best at about $\mathrm{pH} 7.4$ and were definitely depressed at $\mathrm{pH} 6.5$; the rate of contraction was decreased in acid and increased in alkaline media. The segments of uterus showed very slight changes in activity due to $\mathrm{pH}$ changes from 6.8 to 8.0 . The uterus of the rabbit was noticed to be less sensitive to $\mathrm{pH}$ changes than that of the guinea pig; when placed in a bath with a constant $\mathrm{pH}$ between 7.3 and 7.5 the rabbit uterus exhibted a more constant tonus than the guinea pig uterus. A decrease in $\mathrm{pH}$ caused a relaxation of the tonus of the rabbit uterus, with a decreased rate and increased amplitude of the rhythmical contractions.

The duodenum showed in approximately one segment out of every four an atypical response to successive equivalent doses of adrenalin (fig. 1, a) This response was noticed to a lesser extent in the jejunum (one segment out of every six), to a still lesser extent in the ileum than in the jejunum (one segment out of every eight), and least of all intestinal segments in the colon. It occurred in the uterus in about one segment out of every eight. This atypical response manifested itself in that repeated doses of equal amounts of the drug produced successively smaller depressions until, after six to eight doses, no response to the drug could be elicited (even when the dose was doubled or tripled). Care was taken that the tissue had fully recovered from the last dose before another dose was given. This could not be eliminated by changing from the fresh chloretone-drug solution to the tablet solution for a source of the drug, although it seemed to occur more often when using the latter. It also occurred regardless of the 

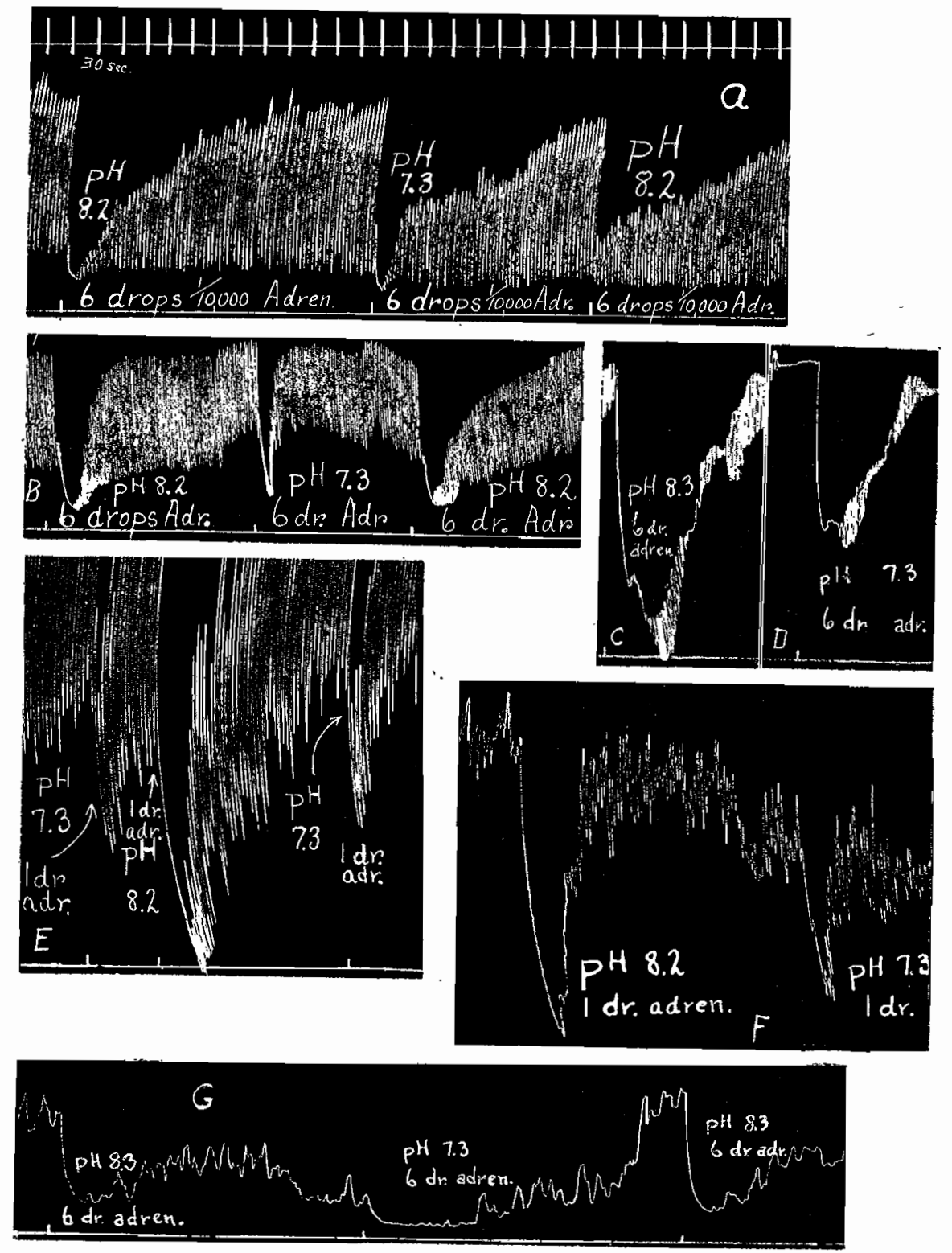

Fig. 1. a. Duodenum. To illustrate the "drug action fading phenomenon" encountered, in that repeated equivalent doses of adrenalin produce successively smaller depressions of tonus and amplitude of contractions.

b, c, d, e. Duodenum. To show the greater and more prolonged depression of tonus and rhythmical contractions in basic then in acid bath as coused by adrenalin, as well as individual differences in gut activity.

f. Ileum. Results similar to those found in duodenum.

g. Colon. Showing that the tonus depression caused by adrenalin is more rapid, and of greater extent but of shorter duration in basic bath and that the depressed rhythmical contractions and tonus recover more slowly at the lower pH level.

methods employed in preparing the segments (see methods above). It was noticed that it could not be eliminated by using Ringer's mammalian solution or Tyrode's solution instead of Locke's solution. A possible diet factor was eliminated because rabbits which showed no such phenomena were receiving the same diet at the same hour as those in which it occurred. No difference in the response according to sex could be seen. Repeatedly renewing the bath or substituting an acid bath for a basic bath would not eliminate it. This phenomenon seemed to be a characteristic of the tissue rather than of the animal, in that, e.g., the duodenum from a certain animal would show it while the uterus from this same animal would fail to do so. In the absence of it the depressions caused by equivalent successive doses on a given segment were equal (i.e., when the $\mathrm{pH}$ of the bath was constant, etc), and could be duplicated again and again until 20 to 30 doses had been given, when the tissues would begin to be sluggish and inactive.

As far as quantitative and qualitative comparisons of the action of adrenalin on the tissues at different $\mathrm{pH}$ levels are concerned, only those in which there was an absence of the "drug action fading phenomenon" will be mentioned.

DuODENum. On this tissue equivalent doses of adrenalin produced a greater and more rapid depression of tonus with slower recovery at $\mathrm{pH}$ 8.2 than at $\mathrm{pH} 7.3$ (fig. 1, b, c, d, e). Especially was this observed when using tissues which were very sensitive to the drug (e.g., showing a marked depression by $1 / 25,000,000$ adrenalin). The amplitude of the rythmical contractions after a depression returned more slowly to normal at $\mathrm{pH} 8.2$ than at $\mathrm{pH}$ 7.3. The rate of the rhythmical contractions was not affected by the drug at any pH. A marked contrast could be seen between the effect of the drug on the tissue at $\mathrm{pH} 8.2$ and at $\mathrm{pH} 7.3$ (fig. $1, \mathrm{e}$ ). In a minority of cases equivalent doses of adrenalin in acid bath would cause a depression of tonus to a lower absolute level than in basic bath, but since the tonus in the basic bath was the higher before the drug was added, the total depression in the basic bath was the more marked. Some segments of duodenum showed periodic variations in amplitude much better than others, and a few segments showed no variations at all. The amplitude variations could be augmented by alkalinization and diminished (but not removed) by acidification (within the $\mathrm{pH}$ limits used). The less active phase in amplitude in acid media would often be seen as nearly a straight line (fig. 1, c, d). However, such segments showed a more marked initial depression in the basic than in the acid bath (fig. 1, c, d). Such strips were also very erratic in their tonus levels.

Jejunum. With this tissue the results were similar to those mentioned above with the duodenum. In dealing with these segments attempts were made to add the drug during the more active periods in the amplitude cycles. However, it was found that such precautions were not altogether 
necessary, since the depressions when effected during the relatively inactive periods in the amplitude cycles seemed to be just as marked as when effected during the active stages. On the other hand it was found that such a precaution is demanded when using uterine segments in order to get consistent results.

Ileum. With segments of ileum, there was a greater and more prolonged depression of tonus, and a longer inhibition of the rhythmical contractions at $\mathrm{pH} 8.2$ than at $\mathrm{pH} 7.3$ (fig. 1, f). The rate of the rhythmical contractions was not affected much in either the acid or basic bath by the addition of the drug. Segments were found which showed no inhibition of rhythmical contractions or depression of tonus at a $\mathrm{pH}$ of 7.3 and which with an equivalent dose showed a marked inhibition of rhythmical contractions and depression of tonus at $\mathrm{pH} 8.2$ even though the gut was contracting actively in both cases. A minority of segments of ileum showed an increased tonus on acidification, especially after the drug had been added on previous occasions to the bath.

Colon. Segments of colon were found to show a marked sensitivity to changes in $\mathrm{pH}$ as far as tonus was concerned (fig. 1, g). An increase in $\mathrm{pH}$ caused a marked increase in tonus while a decrease in $\mathrm{pH}$ showed just the reverse. In a minority of segments the tonus remaned fairly constant as long as the air supply, temperature, and $\mathrm{pH}$ were not changed, while most of the segments were very variable in their tonus levels. When the segments were removed from the animal and immediately mounted, they would in most cases begin their rhythmical contractions immediately, usually with greater amplitude than they would show if allowed to stand in a refrimerator for 24 hours. Apparently the segments were not absolutely tonically contracted upon immediate removal from the body. However, segments which had been contracting in the bath for 4 to 5 hours or which stood for 24 hours in the refrigerator did have a slightly more relaxed tonus which coincides with the observation of Thienes (1926), probably accounting for our observation that the fresh tissues showed, upon adding the drug, greater drops in tonus than the 24 hour tissues. Evidently the 24 hour tissues (being more relaxed than the fresh ones) are not as capable of further relaxation by the drug as the fresh ones. Equivalent additions of the drug produced a more sudden and greater (since tonus was higher) drop of tonus in the alkaline than in the acid bath (fig. 1, g) However, the lowest absolute level of the depressed tonus was lower in the acid bath even though the fall was not so great. The depressed tonus (i.e., depressed by drug) showed a much slower recovery in the acid media, the effect of the drug apparently being more prolonged at the lower $\mathrm{pH}$ level (fig. 1, g). The rate of the rhythmical contractions was not affected by the drug at any $\mathrm{pH}$ tried, although the recovery of the depressed rhythmical contractions was faster in the alkaline bath (fig. 1, g). The maximum tonus depressant action of the drug seemed to occur at about $\mathrm{pH}$ 7.2. Evidently the recovery of a tonus (depressed by adrenalin) which is low before the addition of the drug (as in acid media) is slower than when the tonus is high to begin with (as in basic media). The lower absolute limit of tonus depression by equivalent doses in a minor number of segments appeared about the same at $\mathrm{pH} 7.3$ and 8.3. The latent period appeared shorter at a $\mathrm{pH}$ of 8.3 than at a $\mathrm{pH}$ of 7.3 (fig. $1, \mathrm{~g}$ ).

Uterus. The uterus showed a nearly constant tonus, regardless of the $\mathrm{pH}$ (i.e., between $\mathrm{pH}$ levels 7.2 and 8.3). A few segments showed an increase of tonus on decreasing the $\mathrm{pH}$, especially after previous doses of adrenalin had been given. In practically all of the segments employed no difference in the action of the drug could be elicited even in changes of $\mathrm{pH}$ from 7.0 to 8.3. A minor number of segments showed a higher stimulatory rise of tonus at $\mathrm{pH}$ of 8.2 than at $\mathrm{pH} 7.3$, but in these cases the durations of the tonus changes and amplitude inhibitions were similar. It appears that the $\mathrm{pH}$ factor plays a relatively small part here, when one deals with variations between 7.0 and 8.3 .

Discussion. It is well known that adrenalin is oxidized more rapidly in the oxygenated alkaline than in the oxygenated acid bath. This might be thought to cause a less prolonged depressant action in alkaline media (especially if we had been using large doses of the drug), but this latter fact was not observed to be the case with the gut segments used. Perhaps this factor does not enter into the physiological response of the tissues. Most of the tissues used in these experiments seemed to withstand excesses of alkali better than excesses of acid (between $\mathrm{pH}$ levels 6.8 and 8.3 as lower and upper limits). Possibly the ionized calcium in the bath may play a part in this latter fact and in the variable responses at different $\mathrm{pH}$ levels especially if we had employed Tyrode's instead of Locke's solution. It may be added that it is quite essential that one take into consideration the $\mathrm{pH}$ of the various tissues in order to more fully appreciate the rôle of $\mathrm{pH}$ in affecting the action of adrenalin on the "myoneural junction."

Evidently the inhibitory innervation to the intestine responds to adrenalin at various $\mathrm{pH}$ levels with similar differences as does the vasoconstrictor mechanism, while that to the large intestine responds with differences reverse from those of the small intestine to a certain extent. The loss of tonus of the colon at a low $\mathrm{pH}$ probably accounts for its slower recovery when the inhibitory mechanism is stimulated in the more acid medium.

SUMMARY

The results of Evans and Underhill (1923) on the activity of segments of small intestine and uterus when the $\mathrm{pH}$ of the bath is changed are confirmed. Segments of colon were found to show a marked sensitivity to 
changes in $\mathrm{pH}$ as far as tonus is concerned. An increase in $\mathrm{pH}$ caused a marked rise in tonus while a decrease in $\mathrm{pH}$ caused the reverse (between 7.0 and 8.2). The tonus remained constant as long as the air supply, temperature, and $\mathrm{pH}$ were unchanged. It was possible to vary the tonus of fresh tissues by drug additon more than of tissue 24 hours old. The segments of uterus showed very slight changes in activity due to changes in $\mathrm{pH}$ from 6.8 to 8.3 .

Isolated segments of duodenum (more so than those of jejunum, ileum, colon, and uterus, in the order of occurrence) show in about one case out of every four an irregularity in response to adrenalin in that successive doses produce progressively diminishing responses even though an equivalent dose of freshly prepared drug is given each time.

In the absence of this drug action fading phenomenon segments of duodenum, jejunum, and ileum show in most cases after equivalent additions of the drug to the bath at a $\mathrm{pH}$ of 8.2 an earlier, greater, more rapid, and more prolonged depression of tonus with a slower recovery of the amplitude of the rhythmical contractions than at a $\mathrm{pH}$ of 7.3. The rate of the rhythmical contractions is not affected by the drug at any $\mathrm{pH}$ between 7.0 and 8.3. An optimum $\mathrm{pH}$ for the depressant action of a minimal dose of adrenalin on these tissues is thought to exist at about 7.8.

In the absence of the drug action fading phenomenon, segments of scybalar colon show in most cases after equivalent additions of the drug to the bath at a $\mathrm{pH}$ of 8.3 a greater fall of tonus than at a $\mathrm{pH}$ of 7.2. The recovery of depressed tonus and depressed rhythmical contractions is more rapid at a $\mathrm{pH}$ of 8.3 than at a $\mathrm{pH}$ of 7.2. The rate of the rhythmical contractions is not affected by the drug at any $\mathrm{pH}$ between 7.0 and 8.3. An optimum $\mathrm{pH}$ for the depressant action of a minimal dose of adrenalin on the colon is thought to exist at about 7.3.

These observations are in agreement with the previous findings as regards the vasoconstrictor mechanism.

Segments of non-pregnant rabbit uterus show no difference in response to minimal stimulatory doses of adrenalin at various $\mathrm{pH}$ levels ranging from 7.0 to 8.3 .

\section{BIBLIOGRAPHY}

Acton, H. W. and R. N. Chopra. 1925. Indian Journ. Med. Res., xii, 443.

Burget, G. E. and M. B. Visscher. 1927. This Journal, lxxxi, 113.

Burget, G. E. and G. Crisler. 1927. This Journal, lxxxiii, 373.

Dale, H. H. and C. L. Evans. 1920. Journ. Physiol., liv, 167.

Evans, C. L. and S. W. F. Underhill. 1923. Journ. Physiol., lviii, 1.

McCrudden, F. H. 1922. Weekly Public Health Repts., xxxvii, 334.

Sollmann, T., W. F. von Oettingen and Y. Ishikawa. 1928. This Journal, lxxxvi, 661 .

Thtenes, C. H. 1926. Arch. Intern. Pharm. et Therap., xxxi, Fasc. v-vi, 447. 